\title{
To Study the Occurrence of Non-Alcoholic Fatty Liver Disease (NAFLD) in Type 2 Diabetes Mellitus.
}

\author{
Siddharth Arya ${ }^{1}$, Jigar M. Haria ${ }^{2}$, Amit Mishra ${ }^{3}$ \\ ${ }^{1}$ Post Graduate Student, Department of Medicine, Teerthanker Mahaveer Medical College \& Research Centre, ${ }^{2}$ Professor, Department of Medicine, \\ Teerthanker Mahaveer Medical College \& Research Centre, ${ }^{3}$ Assistant Professor, Department of Medicine, Teerthanker Mahaveer Medical College \& \\ Research Centre.
}

\section{Abstract}

Background: Macrovascular and Microvascular complications are well evaluated in DM but NAFLD is the most neglected and unevaluated complication among DM.Fibroscan is the non-invasive method for assessing liver fibrosis which has high reproducibility and accuracySubjects and Methods: It was a Case Control study. Fibrosis was assessed by fibroscan and was then quantified. Results: In our study there was a significant difference seen among the different grades of fibrosis among controls and cases ( $\mathrm{p}=0.004)$. The mean fibrosis score too was high among cases (13.498) as compared to controls (6.052). The overall prevalence of NAFLD (F2-F4) was found to be 50\% among cases as compared to $14 \%$ in controls.Conclusion: Diabetes has a significant etiological role in occurrence of NAFLD in population. Fibroscan has a substantial role in screening and diagnosing diabetics for NAFLD and fibrosis, thus advocating its use is recommended to prevent understudied and unrecognized complication of DM preventing mortality and morbidity.

Keywords: NAFLD, Diabetes, Fibroscan,LSM, Fibrosis.

Corresponding Author: Dr. Jigar M. Haria, Professor, Department of Medicine, Teerthanker Mahaveer Medical College \& Research Centre, Moradabad.

Received: December 2019

Accepted: December 2019

\section{Introduction}

NAFLD is spiking the clinical importance lately, due to increased inclination towards sedentary life style \&rising trend of diabetes in our country with huge negligence in understanding the severity of the disease.Diabetics are usually screened for the known complications both macro and microvascular. Majority of the time patients are neglected for liver related complications that manifests as NAFLD, which is the silent complication on rise. NAFLD (Non- alcoholic liver disease) is gamut extending from NAFL (non- alcoholic fatty liver) to NASH (non- alcoholic steato-hepatitis), which has proclivity to evolve to liver cirrhosis, hepatocellular carcinoma (HCC). ${ }^{[1]}$

Liver biopsy is the gold standard for establishing NAFLD but being an invasive technique it is usually not accepted by patients and related to even complications, hence a noninvasive technique is needed. Transient elastography by Fibroscan is the non-invasive method for assessing liver fibrosis which has high reproducibility and accuracy. ${ }^{[2]}$

$\underline{\text { Aim }}$

- To study the occurrence of NAFLD (Non-Alcoholic Fatty Liver Disease) in Type 2 Diabetes Mellitus.

\section{Objectives}

- To screen Type 2 Diabetes Mellitus patients for Liver Stiffness Measure (LSM) by Fibroscan.
To study various correlates of LSM in Type 2 Diabetes Mellitus patients.

\section{Subjects and Methods}

This study was conducted in the Department of Internal Medicine, Teerthanker Mahaveer Medical College and Research Centre, Moradabad. Our study is of Case-control type which was done over the span 1 year. Fifty cases and Fifty controls were taken from both OPD and IPD setting in TMMC \& RC, Moradabad, U.P. Patients were selected on the basis of Inclusion \& Exclusion criteria.

\section{Inclusion Criteria}

a) Cases: Patients aged from $\geq 18$ years up to 70 years with type 2 diabetes who attended OPD and admitted in IPD at Teerthanker Mahaveer Medical College \& Research Centre, Moradabad are considered as Cases.

b) Controls: Patients aged from $\geq 18$ years up to 70 years without diabetes who attended OPD and admitted in IPD at Teerthanker Mahaveer Medical College \& Research Centre, Moradabad are considered as Controls.

\section{Exclusion Criteria}

a. Subjects who are known case of malignancy,

b. HbsAg Positive (hepatitis B surface antigen) or Anti HCV reactive (antibody against hepatitis $\mathrm{C}$ virus), 
c. Other causes of fatty liver (eg, consumption of amiodarone and tamoxifen) are excluded,

d. Males who had intake of $>20 \mathrm{~g}$ and women who had intake of $>10 \mathrm{~g}$ of alcohol over 24 hours are excluded

\section{Case definition}

Cases will be who are known case of diabetes mellitus (taking oral hypoglycemics) or newly diagnosed and newly diagnosed will diagnosed by following criteria: ${ }^{[3]}$

$>$ Symptoms of diabetes plus random blood glucose concentration $\geq 11.1 \mathrm{mmol} / \mathrm{L}(200 \mathrm{mg} / \mathrm{dL})$ or

$>$ Fasting plasma glucose $\geq 7.0 \mathrm{mmol} / \mathrm{L}(126 \mathrm{mg} / \mathrm{dL})$ or

$>\mathrm{HbAlc} \geq 6.5 \%$ or

$>$ 2-h plasma glucose $\geq 11.1 \mathrm{mmol} / \mathrm{L}(200 \mathrm{mg} / \mathrm{dL})$ during an oral glucose tolerance test

\section{Methodology}

All the subjects, relevant detailed history was obtained along with salient clinical findings according to the pre-designed proforma, FIBROSCAN and laboratory reports of the patients was collected and analyzed. All the cases and controls underwent Fibroscan which is non-invasive method for assessing Liver Fibrosis which is measured in $\mathrm{kPa}$ (kilo Pascals) by using suitable probe. Face-to-face interviews from both cases and controls and records. Data which was collected, was entered in Microsoft Excel Word Spreadsheet on regular basis. Data was organized in tabular form. Data was evaluated using SPPS version 18. Significant tests were applied. The difference was considered statistically significant at $\mathrm{p}<0.05$.

\section{Results}

The results of our study are enlisted below. The various demographical profile of our subjects is tabulated [Table 1]. The distribution of diabetics and non-diabetics among urban and rural areas. 64\% diabetics were residing in urban areas in vicinity of Moradabad and adjacent districts in comparison to $36 \%$ cases who were residing in rural areas. Non-Diabetics $52 \%$ were residing in rural areas whereas $48 \%$ controls were residing in urban areas.

\begin{tabular}{|c|c|c|c|}
\hline \multicolumn{4}{|c|}{ Table 1: Demographic Profile of Subjects } \\
\hline Variables & Sub-groups & Total $(n=100)$ & Percentage $(\%)$ \\
\hline \multirow{6}{*}{$\begin{array}{l}\text { Age (in } \\
\text { years) }\end{array}$} & $18-30$ & 14 & 14 \\
\hline & $31-40$ & 22 & 22 \\
\hline & $41-50$ & 30 & 30 \\
\hline & $51-60$ & 21 & 21 \\
\hline & $>60$ & 13 & 13 \\
\hline & Mean \pm SD & $45.83 \pm 12.65$ & \\
\hline \multirow[t]{2}{*}{ Gender } & Female & 49 & 49 \\
\hline & Male & 51 & 51 \\
\hline \multirow{4}{*}{$\begin{array}{l}\text { Education } \\
\text { Qualification }\end{array}$} & Illiterate & 48 & 48 \\
\hline & Primary & 30 & 30 \\
\hline & High School & 15 & 15 \\
\hline & Graduate & 7 & 7 \\
\hline \multirow{2}{*}{$\begin{array}{l}\text { Marital } \\
\text { Status }\end{array}$} & Unmarried & 12 & 12 \\
\hline & Married & 88 & 88 \\
\hline \multirow[t]{2}{*}{ Religion } & Hindu & 55 & 55 \\
\hline & Muslim & 45 & 45 \\
\hline \multirow[t]{2}{*}{ Residence } & Rural & 44 & 44 \\
\hline & Urban & 56 & 56 \\
\hline
\end{tabular}

Table 2: Comparison between Cases and Controls among different liver stiffness groups

\begin{tabular}{|c|c|c|c|c|c|c|c|c|c|c|c|c|}
\hline \multirow[t]{3}{*}{ Variable } & \multirow{3}{*}{$\begin{array}{l}\text { Type of } \\
\text { case }\end{array}$} & \multicolumn{10}{|c|}{ Fibrosis Grade } & \multirow{3}{*}{$\begin{array}{l}P \\
\text { value }\end{array}$} \\
\hline & & \multicolumn{2}{|l|}{ F0 } & \multicolumn{2}{|l|}{ F1 } & \multicolumn{2}{|l|}{ F2 } & \multicolumn{2}{|l|}{ F3 } & \multicolumn{2}{|l|}{ F4 } & \\
\hline & & Mean & $\begin{array}{l}\text { Std. } \\
\text { Deviation }\end{array}$ & Mean & $\begin{array}{l}\text { Std. } \\
\text { Deviation }\end{array}$ & Mean & $\begin{array}{l}\text { Std. } \\
\text { Deviation }\end{array}$ & Mean & $\begin{array}{l}\text { Std. } \\
\text { Deviation }\end{array}$ & Mean & $\begin{array}{l}\text { Std. } \\
\text { Deviation }\end{array}$ & \\
\hline \multirow[t]{2}{*}{ Age } & Cases & 52.06 & 9.98 & 52.00 & 10.92 & 50.40 & 5.90 & 50.00 & 10.61 & 53.87 & 9.49 & \multirow[t]{2}{*}{$<0.001$} \\
\hline & Controls & 38.30 & 11.73 & 43.00 & 15.97 & 39.25 & 14.10 & 43.50 & 14.20 & 39.67 & 12.66 & \\
\hline \multirow[t]{2}{*}{ BMI } & Cases & 22.47 & 2.84 & 25.68 & 5.77 & 23.66 & 5.05 & 28.56 & 6.95 & 26.61 & 6.27 & \multirow[t]{2}{*}{0.472} \\
\hline & Controls & 23.48 & 4.22 & 28.70 & 3.56 & 22.05 & 4.39 & 25.58 & 6.77 & 25.60 & 5.38 & \\
\hline \multirow[t]{2}{*}{ SGOT } & Cases & 28.06 & 13.75 & 23.00 & 12.51 & 22.20 & 6.94 & 43.40 & 20.50 & 58.09 & 45.11 & \multirow[t]{2}{*}{0.208} \\
\hline & Controls & 32.33 & 14.98 & 40.73 & 27.24 & 390.25 & 470.10 & 44.50 & 16.98 & 66.33 & 26.41 & \\
\hline \multirow[t]{2}{*}{ SGPT } & Cases & 32.56 & 19.55 & 28.56 & 22.23 & 24.80 & 14.31 & 47.00 & 25.00 & 59.69 & 47.41 & \multirow[t]{2}{*}{0.175} \\
\hline & Controls & 38.55 & 29.45 & 50.40 & 53.17 & 361.00 & 416.50 & 43.25 & 18.03 & 75.00 & 74.51 & \\
\hline \multirow[t]{2}{*}{$\mathrm{Hb}$} & Cases & 11.88 & 1.67 & 11.53 & 1.89 & 8.74 & 2.42 & 11.14 & 0.85 & 11.27 & 2.86 & \multirow[t]{2}{*}{0.001} \\
\hline & Controls & 12.71 & 2.27 & 13.32 & 1.41 & 10.70 & 2.41 & 13.13 & 1.77 & 13.77 & 2.15 & \\
\hline \multirow[t]{2}{*}{ SBP } & Cases & 122.38 & 11.51 & 121.33 & 14.93 & 128.00 & 21.68 & 149.20 & 18.79 & 126.53 & 19.03 & \multirow[t]{2}{*}{0.459} \\
\hline & Controls & 122.18 & 14.52 & 128.00 & 14.97 & 116.50 & 13.99 & 136.00 & 24.87 & 133.33 & 15.28 & \\
\hline \multirow[t]{2}{*}{ DBP } & Cases & 74.88 & 7.93 & 77.11 & 8.95 & 80.00 & 14.14 & 92.80 & 12.46 & 78.53 & 10.10 & \multirow[t]{2}{*}{0.659} \\
\hline & Controls & 76.61 & 9.96 & 82.00 & 9.80 & 75.00 & 5.77 & 84.50 & 12.69 & 76.67 & 11.55 & \\
\hline
\end{tabular}

BMI, body mass index; SGOT, serum glutamate oxaloacetic transaminase; SGPT, serum pyruvate transaminase; Hb,hemoglobin;SBP,systolic blood pressure; DBP, diastolic blood pressure

Our study depicts the distribution of Hemoglobin as mean $\mathrm{Hb}$ value among cases was $11.244 \pm 2.25$ whereas among controls the mean $\mathrm{Hb}$ was $12.720 \pm 2.19$, mean SGOT value among cases was $37.11 \pm 30.46$ juxtaposed to controls was $64.99 \pm 152.51$, SGPT mean values among cases was $40.65 \pm 33.11$ in comparison to controls was $68.33 \pm 139.30$. Our study also depicts the distribution of cases and controls according to hypertension as following i.e. $74 \%$ did not have hypertension out of which $38 \%$ were cases and $36 \%$ were controls, $26 \%$ had hypertension out of which $24 \%$ were cases and $28 \%$ were controls. [Table 2]

The distribution of duration of DM was as $46 \%$ in time span of 6-10 years of duration of DM , 38\% in time span of 1-5 years of duration of DM, $16 \%$ in time span of $>10$ years of 
duration of DM. The mean duration of DM in our study was 7.52 +/- 4.46 years with no significant variation among different fibrosis grade.

Table 3: Distribution of subjects according to NAFLD on Fibroscan. ${ }^{[4]}$

\begin{tabular}{|c|c|c|c|c|}
\hline $\begin{array}{l}\text { Fibrosis Grade } \\
(\mathrm{kPa})\end{array}$ & $\begin{array}{l}\text { Cases } \\
(\%)\end{array}$ & $\begin{array}{l}\begin{array}{l}\text { Control } \\
(\%)\end{array} \\
\end{array}$ & $\begin{array}{l}\text { Total } \\
(\%)\end{array}$ & $\begin{array}{l}\text { p- } \\
\text { value }\end{array}$ \\
\hline F0 (0-5.9) & $16(32 \%)$ & $33(66 \%)$ & $49(49 \%)$ & \multirow{6}{*}{$\begin{array}{l}\mathrm{P}=0.00 \\
4\end{array}$} \\
\hline F1 (6-6.9) & $9(18 \%)$ & $6(12 \%)$ & $15(15 \%)$ & \\
\hline F2 (7-8.6) & $5(10 \%)$ & $4(8 \%)$ & $9(9 \%)$ & \\
\hline F3 (8.7-10.2) & $5(10 \%)$ & $4(8 \%)$ & $9(9 \%)$ & \\
\hline $\mathrm{F} 4(>10.3)$ & $15(30 \%)$ & $3(6 \%)$ & $18(18 \%)$ & \\
\hline Mean \pm SD & $\begin{array}{l}13.498 \pm 17 . \\
18\end{array}$ & $\begin{array}{l}6.052 \pm 2.0 \\
8\end{array}$ & $\begin{array}{l}9.775 \pm 12.7 \\
3\end{array}$ & \\
\hline
\end{tabular}

Our study shows us a statistically proven alliance among insulin users with LSM (p-: 0.016). All the cases were using oral anti diabetics drugs but among cases only $24 \%$ were using insulin. It was observed that LSM was towards higher side amid insulin users when juxtaposed to non-insulin users. The distribution of Diabetics as per the quantification of HbA1c levels and the mean HbA1c level among diabetics in our study is $9.51+/-2.43$. It was also seen that there was no significant variance seen among the HbAlc levels and mean score of LSM ( $\mathrm{p}=0.144)$. Moreover, the mean score did not have significant variation for different fibrosis grades.

There was a significant difference seen among the different grades of fibrosis among controls and cases in our study $(\mathrm{p}=0.004)$. Among cases F4 grade of fibrosis was seen in $30 \%$ subjects whereas it was seen only in $6 \%$ in controls. The mean fibrosis score was high among cases (13.498) as compared to controls (6.052). [Table 3] The grading used for fibrosis was based on the basis used by Wong et al. as mentioned in [Table 3]

Our study depicts the distribution of BMI among cases and controls as follows i.e among diabetics (cases) $40 \%$ were quantified as obese, $30 \%$ were quantified as normal, $22 \%$ were quantified as overweight, $8 \%$ were quantified as underweight. Among Non-Diabetics (controls) $48 \%$ were quantified as obese, $28 \%$ were quantified as normal, $14 \%$ were quantified as overweight, $10 \%$ were quantified as underweight.

There was no significant difference seen between mean blood fasting glucose levels and different fibrosis groups. The mean duration of fasting blood glucose levels among cases was $160.32 \mathrm{mg} / \mathrm{dl}$ with no significant variation among different fibrosis grade.

\section{Discussion}

In our study the prevalence of NAFLD was found to be $50 \%$ among cases (diabetics) and 22\% among controls (nondiabetics). The study place, Moradabad, displayed that the NAFLD was more prevalent among diabetics with statistically significant relationship. In a study by Agarwal AK. et al, ${ }^{[5]} 124$ participants (74 males \& 50 females) with T2DM were assessed, with prevalence of NAFLD being $57.2 \%$.

In our study the mean age of cases having fibrosis was 50.4 years (F2), 50 years (F3) and 53.87 years (F4). In a study done by Tomeno $\mathrm{W}$ et $\mathrm{al},{ }^{[6]}$ there were a total of 27 participants who had NAFLD, out of which 12 were males and 15 females, the mean age group of participants having NAFLD in this study was $55.8 \pm 14.9$ years.

\section{BMI and Fibrosis}

In our study $62 \%$ cases and $62 \%$ controls had higher BMI for their age and height. Our study previewed no significant difference $(p=0.472)$ between BMI and different fibrosis grades among cases and controls. Patients with high BMI and diabetes are the ideal patient to undergo Fibroscan to assess fibrosis.

\section{HbA1c and Fibrosis}

It was seen that there was no significant difference seen among the HbA1c levels and mean score of LSM $(p=0.144)$ in our study. Moreover, the mean score did not have significant variation for different fibrosis grades among cases. This can be explained by the concept that LSM which is an irreversible entity and HbAlc which can vary with treatment, so significant relationship is unlikely to be present.

\section{Fibroscan and NAFLD}

In our study there was a significant difference seen among the different grades of fibrosis among controls and cases $(\mathrm{p}=0.004)$. Among cases F4 grade of fibrosis was seen in $30 \%$ subjects whereas it was seen only in $6 \%$ in controls. The mean fibrosis score too was high among cases (13.498) as compared to controls (6.052). The overall prevalence of NAFLD (F2-F4) was found to be $50 \%$ among cases as compared to $14 \%$ in controls. This result concluded that diabetes plays a pivotal role in occurrence of NAFLD. In usual clinical practice fibrosis LSM 7-9kpa is used as grading for NAFLD which amounted to our group F2 and F3, which amounts to $20 \%$ of the diabetic group. Fibroscan being a non-invasive and user-friendly tool, clinicians should use it for liver stiffness assessment in diabetics patients for recognizing the evil effect of DM on liver. It is well known that insulin resistance induces ED (endothelial dysfunction) in liver which progresses to state of pro-fibrogenic, proinflammatory and pro-thrombotic environment impairing the liver repair, progressing to steatosis and further to steatohepatitis and cirrhosis.

\section{Insulin and Fibrosis}

Relation between Insulin and Fibrosis in our Study pictures a statistically proven alliance among insulin users with LSM (p-: 0.016). It was observed that LSM was towards higher side among insulin users when juxtaposed to non-insulin users. It is postulated that poor diabetes control which is explained by administration of insulin and not controlled by Oral Anti Diabetics drugs, can lead to progression to NAFLD and even advanced fibrosis.

\section{Conclusion}

We included the two categories of patients that were diabetics and non-diabetics. They were evaluated and underwent the routine investigations, BMI measurements. 
Arya et al: Occurrence of Nan-Alcahalic Fatty Liwer Disease (NAF LD) in Type 2 Dialhetes Mellitus

The both clusters underwent Fibroscan. There data was collected and tabulated and was analyzed. We then compared our study with various other studies who also studied on the prevalence of NAFLD in Diabetics using various other techniques.

Diabetes has a significant etiological role in occurrence of NAFLD in population. Fibroscan has a substantial role in screening and diagnosing diabetics for NAFLD, therefore advocating its use is recommended to prevent understudied and unrecognized complication of DM preventing mortality and morbidity, by the physicians.

\section{References}

1. Duseja A, Sharma B, Kumar A, Kapil S, Das A, Dhiman RK, et al. Nonalcoholic fatty liver in a developing country is responsible for significant liver disease. Hepatology. 2010 Dec;52(6):2248-9.

2. Sasso M, Beaugrand $M$, deLedinghen $\mathrm{V}$, et al. Controlled attenuation parameter (CAP): a novel VCTE guided ultrasonic attenuation measurement for the evaluation of hepatic steatosis: preliminary study and validation in a cohort of patients with chronic liver disease from various causes. Ultrasound Med Biol 2010; 36:1825-35.

3. American Diabetes Association. Standards of medical care in diabetes-2014. Diabetes Care. 2014 Jan;37Suppl 1: S14-80.

4. Wong VW-S, Vergniol J, Wong GL-H, Foucher J, Chan HL-Y, Le Bail $B$, et al. Diagnosis of fibrosis and cirrhosis using liver stiffness measurement in nonalcoholic fatty liver disease. Hepatology. 2010 Feb;51(2):454-62.

5. Agarwal AK, Jain V, Singla S, Baruah BP, Arya V, Yadav R, et al. Prevalence of non-alcoholic fatty liver disease and its correlation with coronary risk factors in patients with type 2 diabetes. J Assoc Physicians India. 2011 Jun; 59:351-4.

6. Tomeno W, Yoneda M, Imajo K, Suzuki K, Ogawa Y, Shinohara Y, et al. Evaluation of the Liver Fibrosis Index calculated by using real-time tissue elastography for the non-invasive assessment of liver fibrosis in chronic liver diseases. Hepatol Res. 2013 Jul;43(7):735-42.

Copyright: (C) the author(s), 2019. It is an open-access article distributed under the terms of the Creative Commons Attribution License (CC BY 4.0), which permits authors to retain ownership of the copyright for their content, and allow anyone to download, reuse, reprint, modify, distribute and/or copy the content as long as the original authors and source are cited.

How to cite this article: Arya S, Haria JM, Mishra A. To Study the Occurrence of Non-Alcoholic Fatty Liver Disease (NAFLD) in Type 2 Diabetes Mellitus.Acad. J Med. 2019;2(2):207-10.

DOI: dx.doi.org/10.21276/ajm.2019.2.2.52

Source of Support: Nil, Conflict of Interest: None declared. 